\title{
Energy Expenditure and Intensity Levels of Horizontal Climbing in Prepubescent Children
}

\author{
Cyrus W. Darling III ${ }^{1, *}$, Kirk E. Mathias ${ }^{2}$, Charilaos Papadopoulos ${ }^{3}$, James DePaepe ${ }^{4}$, Buddy R. Woodman ${ }^{5}$ \\ ${ }^{1}$ Northshore School District, Seattle Washington \\ ${ }^{2}$ Department of Physical Education, School Health and Movement Studies, Central Washington University, Ellensburg, WA 98926 \\ ${ }^{3}$ School of Education and Kinesiology, Pacific Lutheran University, Tacoma, WA 98447 \\ ${ }^{4}$ Health Sciences, Central Washington University, Central Washington University, Ellensburg, WA 98926 \\ ${ }^{5}$ Kittitas Schools, Kittitas, Washington 98926 \\ *Corresponding author: cdarling@nsd.org
}

\begin{abstract}
According to the most recent National Health and Nutrition Examination Survey data, 75\% of American youth do not participate in moderate to vigorus activity for 60 minutes a day. The $25 \%$ that do participate in rigous activity report: basketball, running and football for boys; and running, walking and basketball for girls. In order to increase participation rates different activity choices need to be offered to youth. Therefore, this study examined the energy expenditure and intensity levels of horizontal climbing in prepubescent children. Fifty-one children (males = 23 , females $=28$ ) aged 6-10 from a rural elementary school in Washington State participated in this study. Data were collected using an Actigraph GT3X triaxial accelerometer. The overall mean MET value was $10.6( \pm 1.4)$ as determined by the sum of all three axes. The collected data revealed that traverse climbing in children aged 6-10 is a vigorous intensive activity. It is recommended that climbing should be included as an effective alternative physical activity to help children meet the daily-recommended minimum of 60 minutes of moderate to vigorous physical activity.
\end{abstract}

\section{Keywords: climbing, energy expenditure, intensity levels, elementary, physical education}

Cite This Article: Cyrus W. Darling III, Kirk E. Mathias, Charilaos Papadopoulos, James DePaepe, and Buddy R. Woodman, "Energy Expenditure and Intensity Levels of Horizontal Climbing in Prepubescent Children." Journal of Physical Activity Research, vol. 2, no. 1 (2017): 39-43. doi: 10.12691/jpar-2-1-7.

\section{Introduction}

Inactive lifestyles continues to be a significant concern dramatically impacting the health and well-being of American society. Beginning with youth, nearly one in three children in the US is obese [1] due to inactivity. The 2007-2008 National Health and Nutrition Examination (NHANE) Survey reported that nearly $20 \%$ of children between 6-11 years of age are obese and the 2014 NHANE survey reported only $25 \%$ of American youth participating in some moderate to vigours activity [2] . According to Ogden \& Carroll [2] obesity rates among 611 year olds have increased $13 \%$ since 1980 . Exacerbating the issue has been advances in technology. The increased opportunity to sit and use technology is simply making all Americans more sedentary [3]. This inactivity combined with easier access to low-nutrient, high fat foods and low moderate-vigorous activity will undoubtedly make the childhood obesity epidemic worse [1]. In turn more adults will develop heart disease, stroke and certain forms of cancer $[3,4]$.

Aside from a nutritional, properly portioned diet, there needs to be an increase in physical activity participation and subsequent intensity levels among today's youth. The US Department of Health and Human Services [3] recommends children accumulate 60 minutes of moderate activity on most days of the week, while The Surgeon General [5] recommends children accumulate 30 minutes of daily activity at a moderate level. Notwithstanding time and frequency, the common demonitator is intensity. Fitness results are achieved when participation is ongoing, therefore it's important to introduce children to activities that are appealing and increase the likelihood of ongoing physical activity participation. Since physical education provides the ability to reach all students in the school it is an ideal place to incorporate a variety of appealing activities that are intensive and can be persued over a lifetime.

The increase in horizontal climbing wall use in public schools [6] makes it an activity worth investigating when referring to increased intensity. Interestingly enough, the increased popularity of climbing walls in physical education have in part been driven on the assumed gains in strength, flexibility and mental toughness [7]. Much of the research has examined simple physiological responses without regard to impact on fitness. The climbing research that exists uses either trained, elite climbers or takes place on a vertical climbing wall. One such study tested four climbing routes ( 3 vertical and 1 traverse) and found that as vertical movement increased, so did heart rate. Intensity levels were not referenced but data collected while climbing was expressed as a percentage of $\dot{\mathrm{V}} \mathrm{O}_{2}$ in 
comparison to running [8]. Two other studies found that adults climb at almost $50 \%$ of their $\max \dot{\mathrm{V}} \mathrm{O}_{2}$ as determined by treadmill $[9,10]$. Sheel, Seddon, Knight, McKenzie and Warburton [11] used cycle ergometry instead of treadmill testing and found similar results. Watts \& Drobish [12] determined a MET value of 8.4 9.0 for vertical climbing in adults by comparing $\dot{\mathrm{VO}}_{2}$ data of vertical climbing to values of previously known activities. Janot, Steffen, Porcari, and Maher [13] tested the heart rates of beginner and recreational climbers and took ratings of perceived exertion. Results differed between groups with pre-climb and during climb heart rates being the highest.

Ridley, Ainsworth and Olds [14] have created a compendium of children's activities that include specific intensity levels but over $60 \%$ of the values were derived from studies using adults. There is little evidence that exists detailing the energy costs of children while climbing and none while climbing horizontally on a traverse wall. Therefore, the purpose of this study was to determine the intensity levels of horizontal climbing in prepubescent children.

\section{Methods}

\subsection{Sample Selection}

Recruitment packets containing information on the study, parent consent form, student assent form and health screening questionnaire were sent home to parents/guardians of all students. Spanish versions were sent to those students whose families were Spanish speakers. All subjects who supplied a signed parent consent form as well as a minor subject assent form were screened for safe participation using the subjects' completed health history questionnaire.

\subsection{Instruments}

The weight of each subject was measured without shoes using a calibrated physician beam scale. Three Actigraph GT3-X triaxial accelerometers, which measure movement on three axis' (Axis $1=$ Vertical (X), Axis $2=$ Vertical (Y), Axis $3=$ Lateral $(\mathrm{Z})$ ), were used to assess movement intensity. Trost [15] reported that accelerometers were the best method of measuring physical activity in children and had been validated against indirect calorimetry as a criterion measure [16]. The counts per minute as determined by the Actigraph (formerly CSA) accelerometer were strongly correlated with energy expenditure determined via indirect calorimetry with correlation coefficients of 0.86 . Van Remoortel et al. [17] also tested the GT3-X for validity against indirect calorimetry and correlation analysis revealed a strong minute-by-minute correlation of $\mathrm{r}=0.79$. The activity monitors were placed at the anterior axillary line of the right hip secured by a non-invasive elastic band and collected a measurement every three seconds. The GT3-X measures accelerations ranging in magnitude from approximately $0.05-2.5$ Gs. A twelve-bit Analog to Digital Converter digitizes the activity monitor's output at a rate of 30 times per second. The signal then passes through a filter and band-limits the accelerometer to the frequency range of $0.25-2.5 \mathrm{~Hz}$. Every sample is then summed over time intervals, specified by the user, called an "epoch". The GT3-X accelerometer has dimensions of $1.5 " x 1.44 " x .70 "(3.8 \mathrm{~cm} \times 3.7 \mathrm{~cm} \times 1.8 \mathrm{~cm})$. The GT3-X also has a USB 2.0 connection that reduces time required to download data. The devise has a rechargeable Lithium Polymer battery that can record data for up 20 days. Data collection was completed on an eight-foot high, horizontal (traverse) climbing wall designed and installed by Everlast Climbing Industries measuring 40 feet in length. A 40foot nylon tape measure was used to determine the total distance climbed for each subject.

\subsection{Measures}

Before each trial an activity monitor was initialized for each subject and synchronized to a clock on the investigators personal computer. Once completed the activity monitor data were immediately downloaded to the ActiLife 5 computer software under the randomly selected identification number. Each subject was instructed to climb the traverse wall for four minutes continuously. Subjects who traversed the entire 40-foot wall before the end of the time, simply climbed horizontally back to the beginning. These laps continued until the 4-minute time period expired. All but one subject was able to climb the entire four-minute duration. Once the subject quit climbing they remained standing next to the climbing wall until the researcher measured the total distance climbed. Protective pads as well as an adult spotter were used to minimize injury in the event of a fall. Once the data were downloaded the accelerometer was re-initialized for the next subject and the process was repeated.

\subsection{Data Analysis}

Mean body weight and mean distance climbed, were determined as well as the Mean MET value from movement in each axis. Each axis produced a MET value, therefore the sum of the three axes was used to determine the total MET value. Using all subjects a mean MET value for traverse climbing was determined. The individual axis count was analyzed with a one way ANOVA. Bonferroni post-hoc analysis was used to determine differences between axes. The total distance climbed for each age group was also analyzed with a one-way ANOVA to determine differences between ages. Again, a Bonferroni post-hoc analysis was used to determine if distances differed between ages. Furthermore, the rate at which each age group climbed was calculated for both gender and age.

\subsection{Subjects}

Fifty-one children (males $=23$, females $=28$ ) aged 6-10 from a rural elementary school in Washington State participated in this study. All subjects were enrolled in one elementary school serving a diverse population.

\section{Results}

Of the 51 subjects, 49 had complete data (males $=23$, females $=26$ ). Two subjects were excluded due to time 
synchronization errors during the data collection process. There were only three subjects in the 6 year old category (1 male, 2 female) so results in this section should be interpreted cautiously as they may or may not be representative of the population. Descriptive statistics for all subjects are summarized in Table 1. The mean age was $8.3( \pm 1.3)$ years and the mean weight for all subjects was $30.1( \pm 6.6) \mathrm{kg}$. For boys the mean weight was $29.9( \pm 5.1) \mathrm{kg}$ while girls had a mean weight of 30.3 $( \pm 7.8) \mathrm{kg}$. Table 2 contains the mean distance climbed in meters. All subjects climbed a mean distance of $26.4( \pm 11)$ meters with boys climbing a mean distance of $27.5( \pm 10.9)$ meters and girls climbing a mean distance of $25.4( \pm 11.2)$ meters. Table 3 contains the mean distance climbed for each gender and age group. The chart reveals that 9 year-old boys climbed a mean rate of $34.8( \pm 5.6)$ meters per minute and was the highest of any boy group. Nine year-old girls climbed a mean total distance of $17.8( \pm 6.6)$ meters, which was the same as 6 year old girls.

Table 1. Descriptive Statistics (Mean \pm SD)

\begin{tabular}{|c|c|c|c|}
\hline Characteristic & Group (N=49) & Boys $(\mathrm{N}=23)$ & Girls $(\mathrm{N}=26)$ \\
\hline Age (yr.) & $8.3 \pm 1.3$ & $8.4 \pm 1.3$ & $8.1 \pm 1.3$ \\
\hline Weight (kg) & $30.1 \pm 6.6$ & $29.9 \pm 5.1$ & $30.3 \pm 7.8$ \\
\hline
\end{tabular}

Table 2. Mean Distance Climbed ( \pm SD)

\begin{tabular}{|c|c|c|c|}
\hline Unit & Group $(\mathrm{N}=49)$ & Boys $(\mathrm{N}=23)$ & Girls $(\mathrm{N}=26)$ \\
\hline Meters & $26.4 \pm 11.0$ & $27.5 \pm 10.9$ & $25.4 \pm 11.2$ \\
\hline Feet & $86.5 \pm 36.0$ & $29.9 \pm 5.1$ & $83.4 \pm 36.7$ \\
\hline
\end{tabular}

Table 3. Mean Distance in Meters Climbed by Age ( \pm SD)

\begin{tabular}{|c|c|c|c|}
\hline Age & Group $(\mathrm{N}=49)$ & Boys $(\mathrm{N}=23)$ & Girls $(\mathrm{N}=26)$ \\
\hline 6 & $16.0 \pm 4.8$ & $12.2 \pm \mathrm{NA}^{*}$ & $17.8 \pm 5.0$ \\
\hline 7 & $21.1 \pm 8.9$ & $22.8 \pm 11.5$ & $19.8 \pm 6.9$ \\
\hline 8 & $23.4 \pm 9.5$ & $21.4 \pm 11.0$ & $24.8 \pm 8.8$ \\
\hline 9 & $27.5 \pm 10.7$ & $34.8 \pm 5.6$ & $17.8 \pm 6.6$ \\
\hline 10 & $36.6 \pm 8.3$ & $33.8 \pm 7.3$ & $40.0 \pm 8.8$ \\
\hline
\end{tabular}

*Only one 6-year old boy subject.

Table 4. Mean Activity Counts per Minute ( \pm SD)

\begin{tabular}{|c|c|c|c|}
\hline Counts per Minute & Group $(\mathrm{N}=49)$ & Boys $(\mathrm{N}=23)$ & Girls $(\mathrm{N}=26)$ \\
\hline Vert (y-axis) & $641 \pm 348$ & $765 \pm 392$ & $531 \pm 267$ \\
\hline Hor (x-axis) & $1500 \pm 469$ & $1690 \pm 471$ & $1331 \pm 405$ \\
\hline Lat (z-axis) & $1746 \pm 520$ & $1898 \pm 531$ & $1612 \pm 481$ \\
\hline
\end{tabular}

Table 5. Mean METs per Axis ( \pm SD)

\begin{tabular}{|c|c|c|c|}
\hline MET Value per Axis & Group $(\mathrm{N}=49)$ & Boys $(\mathrm{N}=23)$ & Girls $(\mathrm{N}=26)$ \\
\hline Vert (y-axis) & $2.8 \pm 0.4$ & $2.9 \pm 0.4$ & $2.7 \pm 0.3$ \\
\hline Hor (x-axis) & $3.8 \pm 0.5$ & $4.0 \pm 0.5$ & $3.6 \pm 0.4$ \\
\hline Lat (z-axis) & $4.1 \pm 0.6$ & $4.2 \pm 0.6$ & $3.9 \pm 0.5$ \\
\hline
\end{tabular}

The mean activity counts per minute, per axis are located in Table 4. Boys accumulated more mean activity counts on all three axes when compared to girls of the same age. Vertical axis climbing produced significantly lower activity counts $(641 \pm 348) \mathrm{p}<.001$ than the horizontal axis $(1500 \pm 469)$, and lateral axis $(1746 \pm 520)$ $\mathrm{p}<.01$ in both boys and girls. The lateral axis (Z-axis) activity counts were significantly higher than the vertical axis (Y-axis) $\mathrm{p}<.001$ and the horizontal axis (X-axis) $\mathrm{p}<.034$. The Freedson Child equation, $($ METs $=2.757+$ $(0.0015 *$ counts per minute $)-(0.08957 *$ age $(\mathrm{yr}))-$ $(0.000038 *$ counts per minute * age $(\mathrm{yr})))$ was used to convert the activity counts of each axis into a quantifiable MET value. The mean MET values for each axis are located in Table 5. Similar to activity counts, the vertical axis required fewer METs $(2.8 \pm 0.4)$ than the horizontal $(3.8 \pm 0.5)$ and lateral $(4.1 \pm 0.6)$ axis in both boys and girls.

Table 6 contains the mean MET value of each axis as they apply to age. The mean horizontal MET value of all ages, except the nine-year olds, is at least one full MET higher than the MET value of the vertical axis. Each mean MET value of the lateral axis is higher than the horizontal and vertical mean MET values for all ages. Table 7 contains the mean MET value of each axis by age and gender. Looking at the horizontal axis of eight-year-old boys and girls we see boys have a mean MET value of 4.1 $( \pm 0.6)$ compared to the girl value of $3.3( \pm 0.4)$. However, when looking at Table 3 we see that eight-year-old girls averaged $24.8( \pm 8.8)$ meters of total distance climbed and eight year old boys averaged 21.4 ( \pm 11.0) meters. Interestingly, the eight-year-old girls, on average, climbed further while using less METs on the horizontal axis.

Table 6. Mean MET Value per Axis by Age ( \pm SD)

\begin{tabular}{|c|c|c|c|}
\hline Age & Vert (y) & Hor (x) & Lat (z) \\
\hline 6 & $2.7 \pm 0.1$ & $3.8 \pm 0.2$ & $3.9 \pm 0.2$ \\
\hline 7 & $2.8 \pm 0.5$ & $3.9 \pm 0.5$ & $4.3 \pm 0.6$ \\
\hline 8 & $2.6 \pm 0.3$ & $3.6 \pm 0.6$ & $3.8 \pm 0.6$ \\
\hline 9 & $2.9 \pm 0.3$ & $3.8 \pm 0.6$ & $4.1 \pm 0.6$ \\
\hline 10 & $2.8 \pm 0.3$ & $3.9 \pm 0.4$ & $4.2 \pm 0.5$ \\
\hline
\end{tabular}

Table 7. Mean MET Value per Axis by Age and Gender ( \pm SD)

\begin{tabular}{|c|c|c|c|}
\hline Boys & Vert (y) & Hor $(\mathrm{x})$ & Lat $(\mathrm{z})$ \\
\hline 6 & $2.7 \pm \mathrm{NA}^{*}$ & $3.6 \pm \mathrm{NA}^{*}$ & $3.8 \pm \mathrm{NA}^{*}$ \\
\hline 7 & $3.0 \pm 0.7$ & $4.0 \pm 0.7$ & $4.4 \pm 0.8$ \\
\hline 8 & $2.8 \pm 0.3$ & $4.1 \pm 0.6$ & $4.2 \pm 0.7$ \\
\hline 9 & $3.1 \pm 0.2$ & $4.2 \pm 0.4$ & $4.4 \pm 0.3$ \\
\hline 10 & $2.8 \pm 0.4$ & $3.9 \pm 0.5$ & $4.1 \pm 0.6$ \\
\hline Girls & & & $4.0 \pm 0.2$ \\
\hline 6 & $2.7 \pm 0.1$ & $3.9 \pm 0.1$ & $4.2 \pm 0.6$ \\
\hline 7 & $2.7 \pm 0.3$ & $3.8 \pm 0.5$ & $3.5 \pm 0.3$ \\
\hline 8 & $2.4 \pm 0.2$ & $3.3 \pm 0.4$ & $3.7 \pm 0.7$ \\
\hline 9 & $2.7 \pm 0.3$ & $3.3 \pm 0.4$ & $4.3 \pm 0.2$ \\
\hline 10 & $2.8 \pm 0.2$ & $3.8 \pm 0.3$ & \\
\hline
\end{tabular}

The subjects moved along three axes. In order to account for all possible movements we added the three axes together and determined a mean sum of all three axes (Table 8). Overall, the boys climbed at a mean intensity level of $11.1( \pm 1.5)$ METs while the girls' mean intensity level was $10.2( \pm 1.6)$ METs. Total METs for the entire subject group, as determined by averaging the sum of all three axes, were $10.6( \pm 1.4)$ (Table 8$)$. When looking at 
the average sum of all three axes by age (Table 9) we see that seven-year old boys $(11.3 \pm 2.1)$ had a slightly higher MET value than seven-year old girls $(10.6 \pm 1.3)$. At age eight the girls' energy expenditure suddenly drops to 9.2 $( \pm 0.8)$ METs while the boys' remains fairly even at $11.1( \pm 1.4)$ METs. Age nine shows little change for girls with a MET value of $9.7( \pm 1.4)$, compared to nine year old boys with a value two METs higher at $11.7( \pm 0.8)$.

Table 8. Mean Sum of 3 Axis by Gender ( \pm SD)

\begin{tabular}{|c|c|}
\hline Gender & Total METs \\
\hline Boy & $11.1 \pm 1.5$ \\
\hline Girl & $10.2 \pm 1.6$ \\
\hline Group & $10.6 \pm 1.4$ \\
\hline
\end{tabular}

Table 9. Mean Sum of 3 Axis by Age (total METs \pm SD)

\begin{tabular}{|c|c|c|c|}
\hline Age & Group $(\mathrm{N}=49)$ & Boys $(\mathrm{N}=23)$ & Girls $(\mathrm{N}=26)$ \\
\hline 6 & $10.5 \pm 0.4$ & $10.2 \pm \mathrm{NA}^{*}$ & $10.6 \pm 0.4$ \\
\hline 7 & $10.9 \pm 1.6$ & $11.3 \pm 2.1$ & $10.6 \pm 1.3$ \\
\hline 8 & $10.0 \pm 1.4$ & $11.1 \pm 1.4$ & $9.2 \pm 0.8$ \\
\hline 9 & $10.9 \pm 1.4$ & $11.7 \pm 0.8$ & $9.7 \pm 1.4$ \\
\hline 10 & $10.8 \pm 1.1$ & $10.8 \pm 1.5$ & $10.9 \pm 0.6$ \\
\hline
\end{tabular}

*Only one 6 year old boy subject.

Measuring total distance allows us to determine a rate at which the subjects climbed. Table 10 includes the climbing rates of both boys and girls. Both genders climbed at a similar rate with boys at a rate of $6.9( \pm 2.7)$ meters per minute and girls at a rate of $6.4( \pm 2.8)$ meters per minute. Overall the entire subject group climbed at a rate of $6.6( \pm 2.7)$ meters per minute..

Table 10. Climbing Rates by Gender ( \pm SD)

\begin{tabular}{|c|c|c|}
\hline Gender & Rate (ft./min.) & Rate (meters/min.) \\
\hline Boy & $22.5 \pm 8.9$ & $6.9 \pm 2.7$ \\
\hline Girl & $20.8 \pm 9.2$ & $6.4 \pm 2.8$ \\
\hline Group & $21.6 \pm 9.0$ & $6.6 \pm 2.7$ \\
\hline
\end{tabular}

\section{Discussion}

Results from this study can be used to help children meet their daily-recommended intensity levels for physical activities. The USDHHS [1] and Surgeon General [5] both recommend moderate intensity activities for children in order to improve health and decrease overall fat-mass. The Actilife 5 program uses the Freedson Child equation to turn recorded activity counts into a MET value. The value we get is not a true measure of intensity but falls within a range determined by the Actilife 5 program. The values and ranges are located in Table 11. The overall MET value for all subjects as determined by the sum of all three axes was $10.6( \pm 1.4)$. Using Table 11 as a guide we can say that traverse climbing in children aged 6-10 is a very vigorous activity.

Ten-year-old subjects climbed significantly $($ p. $<01)$ farther than seven and eight year olds but not nine year olds. The difference in distances climbed could be due to developmental characteristics of the subjects. Nine and 10-year old children have more muscle mass than 7 and 8 -year old children and would produce more muscular strength and endurance leading to more distance climbed. The difference could also be due to the experience level of the subject. This study tested subjects of all ability levels. Subjects who climb regularly will naturally be more efficient with their movements and climb farther than the first-time climber.

Table 11. Climbing Rates (feet per minute \pm SD)

\begin{tabular}{|c|c|c|c|}
\hline Age & Group $(\mathrm{N}=49)$ & Boys $(\mathrm{N}=23)$ & Girls $(\mathrm{N}=26)$ \\
\hline 6 & $13.1 \pm 4.0$ & $10.0 \pm \mathrm{NA}^{*}$ & $14.6 \pm 4.1$ \\
\hline 7 & $17.3 \pm 7.3$ & $18.7 \pm 9.5$ & $16.2 \pm 5.7$ \\
\hline 8 & $19.2 \pm 7.8$ & $17.6 \pm 9.0$ & $20.4 \pm 7.2$ \\
\hline 9 & $22.6 \pm 8.7$ & $28.6 \pm 4.6$ & $14.6 \pm 5.4$ \\
\hline 10 & $30.1 \pm 6.8$ & $27.7 \pm 6.0$ & $32.8 \pm 7.2$ \\
\hline
\end{tabular}

*Only one 6 year old boy subject.

Looking at the MET values of each axis (Table 5) we are able to tell on which plane the subject(s) was most active. There were no significant differences among axes but trials took place on a horizontal wall so we expect the horizontal axis to be towards the higher end of values for the group, and it was at $3.8( \pm 0.5)$ METs. The least amount of movement took place on the vertical axis at 2.8 $( \pm 0.4)$ METs and interestingly the most movement took place on the lateral axis at $4.1( \pm 0.6)$ METs. Based on the MET values per axis it appears subjects spent less time climbing up and down and more time traversing horizontally while intensely holding the wall.

\section{Conclusion}

If children are going to meet the daily-recommended activity guidelines, it is important that they are introduced to fun and challenging activities that they enjoy. The increase in horizontal climbing wall use in public schools [6] made it an activity worth investigating. The increased popularity of climbing walls in physical education have in part been driven on the assumed gains in strength, flexibility and mental toughness [7]. However, no research had been completed to understand the physiological work being experienced by children during climbing.

This study collected some of the first reliable and objective data on the energy expenditure and physical intensity of climbing in children. Based on the results of this study, it may be interpreted that traverse climbing in children aged $6-10$ is a vigorous activity. This suggests that climbing would be an effective physical activity to help children meet the daily-recommended minimum of 60 minutes of moderate to vigorous physical activity.

\section{References}

[1] U.S. Department of Health and Human Services. The Surgeon General's Vision for a Healthy and Fit Nation. Rockville, MD: U.S. Department of Health and Human Services, Office of the Surgeon General, January 2010. 
[2] Fakhouri, T.H.I , Hughes, J.P., Burt, V.L., Song, M, Fulton, J.E. , and Ogden C.L. (2014). Physical activity in U.S. youth aged 12-15, 2012. NCHS Data Brief, No.141, retrieved from https://www.cdc.gov/nchs/data/databriefs/db141.pdf.

[3] Ogden, C., \& Carroll, M. (2010). Prevalence of Obesity Among Children and Adolescents: United States, Trends 1963-1965 Through 2007-2008. National Center for Health Statistics. Retrieved from http://www.cdc.gov/nchs/data/hestat/obesity_child_07_08/obesity child_07_08.htm/.

[4] U.S. Department of Health and Human Services. The Surgeon General's call to action to prevent and decrease overweight and obesity. Rockville, MD: U.S. Department of Health and Human Services, Public Health Service, Office of the Surgeon General, 2001.

[5] Must, A., Jacques, P. F., Dallal, G. E., Bajema, C. J., \& Dietz, W. H. (1992). Long-Term Morbidity and Mortality of Overweight Adolescents. New England Journal of Medicine, 327(19), 1350-1355.

[6] U.S. Department of Health and Human Services. Physical activity and health: A Report of the Surgeon General. Atlanta, GA: U.S. Department of Health and Human Services, Centers for Disease Control and Prevention, National Center for Chronic Disease Prevention and Health Promotion, 1999.

[7] Mittelstaedt, R.D. (1996). Climbing walls are on the rise: risk management and vertical adventures. Journal of Physical Education, Recreation and Dance, 67(7), 31-36.

[8] Mittelstaedt, R. (1997). Indoor climbing walls: the sport of the nineties. Journal of Physysical Education, Recreation and Dance, 68(9), 26-29.

[9] Geus, B.d., O'Driscoll, S.V., \& Meeusen, R. (2006). Influence of climbing style on physiological responses during rock climbing on routes with the same difficulty. European Journal of Applied Physiology, 98, 489-496.
[10] Billat, V., Palleja, P., Charlaix, T, Rizzardo, P., \& Janel, N. (1995). Energy specificity of rock climbing and aerobic capacity in competitive sport rock climbers. The Journal of Sports Medicine and Physical Fitness, 35, 20-24.

[11] Booth, J., Marino, F., Hill, C., \& Gwinn, T. (1999). Energy cost of sport rock climbing in elite performers. British Journal of Sports Medicine, 33, 14-18.

[12] Sheel, A.W., Seddon, N., Knight, A., McKenzie, D.C., \& Warburton, D.E.R. (2003). Physiological responses to indoor rock-climbing and their relationship to maximal cycle ergometry. Medicine \& Science in Sports \& Exercise, 35(7), 1225-1231.

[13] Watts, P. B., \& Drobish, K. M. (1998). Physiological responses to simulated rock climbing at different angles. Medicine and Science in Sports and Exercise, 30(7): 1118-22.

[14] Janot, J.M., Steffen, J.P., Porcari, J.P., \& Maher, M.A. (2000). Heart rate responses and perceived exertion for beginner and recreational sport climbers during indoor climbing. Journal of Exercise Physiology online, 3(1), Retrieved from http://faculty.css.edu/tboone2/asep/JEPjeff.html.

[15] Ridley, K., Ainsworth, B. E., \& Olds, T. S. (2008). Development of a Compendium of Energy Expenditures for Youth. International Journal of Behavioral Nutrition and Physical Activity, 5(1), 45 .

[16] Trost, S. G. (2006). State of the Art Reviews: Measurement of Physical Activity in Children and Adolescents. American Journal of Lifestyle Medicine, 1(4), 299-314.

[17] Trost, S. G., Ward, D. S., Moorehead, S. M., Watson P. D., Riner W., \& Burke J. R. (1998). Validity of the computer science and applications (CSA) activity monitor in children. Medicine and Science in Sports and Exercise 30(4), 629-33.

[18] Van Remoortel H, Raste Y, Louvaris Z, Giavedoni S, Burtin C, et al. (2012). Validity of Six Activity Monitors in Chronic Obstructive Pulmonary Disease: A Comparison with Indirect Calorimetry. PLoS ONE 7(6): e39198. 